\title{
Não matarás a diferença!! "Histórias de leitura” e a experiência do espectador de obras, de Arthur Danto, vistos pela desconstrução.
}

\begin{abstract}
Alexandra Aguirre ${ }^{1}$
Resumo: "Histórias de leitura" são teorias que buscam controlar o sentido da obra ficcional, ao associá-lo à experiência idealizada do leitor; para a desconstrução, uma tentativa de interromper o processo indefinido do movimento da significação. E, é partindo destes pressupostos, que investigamos o espectador de obras, de Arthur Danto, sua experiência, artifício, especificidade.
\end{abstract}

Palavras-chave: desconstrução, experiência, espectador, leitor

\section{Thou shalt not kill the difference!! "Stories of reading" and the experience of spectator of art works, by Arthur Danto, viewed by deconstruction.}

Abstract: "Stories of reading" are theories that seek to control the fictional work meaning, by associating it with the idealized experience of the reader; for deconstruction, an attempt to interrupt the indefinite process of meaning movement. Based on this analysis, we propose to investigate the spectator of art works, by Arthur Danto, its experience, artifice, specificity.

Keywords: deconstrucion, experience, spectator, reader

1 Graduada em Comunicação Social (FACHA), Especialista em História da Arte e da Arquitetura (PUC-Rio), Mestre em Comunicação e Cultura (ECO/UFRJ), Doutora em Ciências Sociais (PPCIS/UERJ), atualmente desenvolve no Programa de História Social da Cultura (PUC-Rio) a pesquisa "Análise desconstrucionista de estudos de recepção e produção de sentido em artes visuais: Athur Danto como centro de irradiação teórica". Pontifícia Universidade Católica (PUC-Rio). E-mail: aguirrealexandra@hotmail.com. Lattes iD: http://lattes.cnpq.br/1391858772568299. Rio de Janeiro, Brasil. 


\section{Introdução}

Este trabalho chama atenção para as "histórias de leituras" como teorias que propõem refletir sobre os sentidos das obras, apoiando-se ora nas estruturas dos textos, ora nas estratégias dos leitores, enquanto experiência de leitura. Porém, afirmar o que há no texto ou na experiência dos leitores não é tarefa simples, nem facilmente descritível, como propõem; e acabam por idealizar e naturalizar a experiência que é o lugar da especificidade, da diferença, a ser ocupado e não dado. Movimentos feministas não associados à desconstrução também contribuem para a desnaturalização do lugar do leitor e sua problematização enquanto especificidade. Utilizamos a noção de "histórias de leituras" para pensar a experiência do espectador de obras, partindo de A transfiguração do lugar-comum, do filósofo da arte Arthur Danto; livro que tampouco é uma "história de leitura", e sim a proposição para uma definição ontológica da arte. No entanto, o que aproxima o livro das teorias acima é sua configuração: toda fundamentação teórica vem sistematicamente acompanhada de hipóteses de espectadores e suas respectivas experiências diante de obras de arte, o que o transforma em uma (quase) "história de leitura". Os espectadores hipotéticos se deparam com a distinção entre obra e objeto - condição ontológica para a definição de arte -, o que faz de suas experiências mais do que meros exemplos ilustrativos da teoria, são o lugar onde esta se resolve; e onde também podemos investigar as oscilações entre operações da obra e estratégias do espectador, suas especificidades, artifícios e onde se dá o controle do movimento próprio da significação.

$\mathrm{Na}$ primeira parte, abordaremos as "histórias de leitura", como elas compreendem a experiência do leitor, e porque a desconstrução as associa ao controle do sentido e da significação. E, na segunda parte, propomos investigar o espectador de $A$ transfiguração..., levando em conta suas diferenças em relação às teorias acima, inclusive entre ficção e obra, leitura e observação de obras. As questões levantadas interessam à medida que problematizam as experiências e o lugar ocupado nelas, o que a tradição filosófica relegou a segundo plano, como a descontinuidade, a mediação e a diferença, em troca do acesso à verdade e ao sentido originário ou definitivo.

\footnotetext{
“Histórias de leitura”, experiência do leitor e os estudos feministas

"Histórias de leitura" é o modo como o teórico crítico da literatura Jonathan
} 
Culler $^{1}$ se refere às teorias que oscilam, frequentemente, em localizar o sentido da obra ficcional entre o texto e a experiência do leitor, com o objetivo de controlar a origem e/ou o sentido final da obra. A experiência do leitor de obras, por exemplo, é frequentemente idealizada como universal e acessível, sem levar em conta a complexidade que é ler, por exemplo, quando as leituras são malsucedidas ou quando não se sai mais "sábio" da experiência de leitura.

Suas histórias seguem um leitor inocente, confiante nas tradicionais hipóteses sobre estrutura e sentido, que se depara com a tortuosidade dos textos, cai em armadilhas, fica frustrado e decepcionado, mas emerge mais sábio pela perda das ilusões. É como se o que permite que se descreva a leitura como uma desventura fosse o final feliz, que transforma uma série de reações em uma compreensão do texto e do self que se engajara no texto. A manipulação do leitor pelo texto dá uma boa história somente se termina bem. ${ }^{2}$

Por outro lado, a obra é frequentemente o ponto de apoio, a parte "estável" da relação à qual o leitor reage. Wolfgang $\mid$ ser $^{3}$, por exemplo, propôs que a Estética da Recepção não apenas deveria deixar as pesquisas empíricas com leitores sobre interpretação da obra, como também romper com a antiga função do crítico de investigador do significado da obra, pois essa não passaria de operação para legitimar a autoridade da crítica. Em seu lugar, o sentido da obra deveria ser investigado na estrutura prévia da obra, à qual o leitor reagiria. Porém, no lugar do antigo significado fixo, a estrutura passou a ocupar este lugar.

Da mesma forma, a noção de um texto com propriedades imutáveis e passíveis de ser descobertas oferece um excelente pano de fundo para discussões sobre a interpretação e ensaios sobre as interpretações que mudam. Os próprios críticos que defendem a crítica orientada para o leitor descobriram que dá uma melhor história falar de textos que convidam ou provocam respostas do que descrever leitores criando textos (...). ${ }^{4}$

A experiência do leitor enquanto reação ao texto que "convida", ou "provoca", funciona por meio de ações cognitivo-sensíveis, como assumir

1 CULLER, Jonathan. Sobre a desconstrução. Teoria e crítica do pós-estruturalismo. Rio de Janeiro: Record, Rosa dos Tempos, 1997

2 CULLER, 1997, p. 94

3 ISER, Wolfgang. O Ato de leitura. São Paulo: Ed. 34, 1996. 2 v.

4 CULLER, 1997, p. 93 
perspectivas, antecipar hipóteses, ter ou não expectativas realizadas, estabelecer conexões e definir contextos, que justificam a agência do leitor diante do texto, em oposição à sua passividade. Essas ações se tomadas como espontâneas tornariam os leitores cínicos, pois após algumas leituras eles perceberiam que assumir perspectivas seria um logro, que hipóteses e expectativas não se concluiriam, e as conexões se contradiriam; ou aprendendo isto, ratificariam estas expectativas, perspectivas e conexões apenas para confirmar o que já sabiam. Quando Roland Barthes propôs em Mitologias ${ }^{5}$ a leitura desmitificadora dos produtos da cultura de massa, afirmava haver uma estratégia nas mensagens produzidas pelas instituições de poder, de apropriação das lutas e conflitos sociais e de sua redução a imagens vazias. O mitólogo decodificaria estas operações, sendo estas o sentido da mensagem.

Para avaliar a carga política de um objeto, e o vazio mítico que o acompanha, nunca devemos nos colocar no ponto de vista da significação, mas sim no ponto de vista do significante, isto é, da coisa roubada, e, dentro do significante, no ponto de vista da linguagem-objeto, isto é, do sentido: não há dúvida de que, se se consultasse um leão real, ele afirmaria que o exemplo de gramática é um estado fortemente despolitizado. ${ }^{6}$

A estratégia do livro de gramática latina, que rouba da fábula sua moral e história, para reduzi-la ao exemplo gramatical, é o que deve ser decifrado pelo mitólogo. Mas, uma vez aprendido isto, o mitólogo teria as mesmas expectativas sobre as estratégias míticas, ou se soubesse que suas hipóteses e expectativas se realizariam, porque confirmar o que já sabe? O exemplo, embora ilustre a experiência idealizada de leitura, pode contradizê-la, pois a experiência do mitólogo pode ser de ordem moral, um dever para a denúncia da cultura de massa, de caráter instrucional em oposição à do leitor desinteressado. No entanto, isto também é um engano, pois a experiência do leitor não precisa ter caráter explicitamente pragmático para ser instrucional; ela é, pelas "histórias de leitura", frequentemente instrucional. A codificação das experiências de leitura nos leva a compreender que longe de ser "espontânea" e "natural" ela se constitui por ações específicas, aprendidas e distintas, que as teorias instruem aos seus leitores. E é esta exclusão de um conjunto de ações não legitimadas que, contraditoriamente, dá o caráter universal, transparente e acessível da experiência do leitor.

5 BARTHES, Roland. Mitologias. 9a Ed. Rio de Janeiro: Ed. Bertrand Brasil, 1993

6 BARTHES, 1993, p. 165 
A experiência das "histórias de leitura" só pode ser compreendida como ocupação de um lugar ou papel altamente artificializado de instrução; o que é explícito para o mitólogo, o é também para aquele que aprende a ocupar o lugar do leitor, processo automatizado e esquecido como artifício. Para a Estética da Recepção, as operações significativas do texto orientam as estratégias interpretativas do leitor, os "atos de apreensão do leitor", que produzirão efeitos estéticos - de estranhamento, suspensão do familiar e do habitual, de caráter imagético e não-verbal, enquanto sentido da obra. O leitor reage às "lacunas" e "indeterminações" do texto, dando sentido à obra, porém, segundo a observação do teórico de literatura Stanley Fish

Lacunas não são inerentes ao texto, mas aparecem (ou não aparecem) em consequência de estratégias interpretativas específicas [...] não há distinção entre o que o texto dá e o que o leitor fornece; ele fornece tudo; as estrelas em um texto literário não são fixas; elas são tão variáveis quanto as linhas que as unem. ${ }^{7}$

A experiência do leitor de ficção é semelhante à do mitólogo que deve identificar os dois níveis da linguagem, estabelecer conexões e contextos, assumir perspectivas, ser levado a criar expectativas para depois perdêlas, etc. - o mesmo caráter instrucional e pragmático. De outra maneira (pergunta já feita ao mitólogo), como produzir efeitos estéticos, função destas ações, uma vez que o leitor esteja consciente dos "percalços" que o espera, senão artificializando este lugar? A noção de que se está descrevendo uma experiência universal, natural ou contínua (e não instruindo a produzir, ocupar, criar), para a desconstrução diz respeito ao controle sobre o sentido da obra; muito do que se diz estar na obra não passa de uma construção da leitura.

Tomadas em conjunto, essas histórias de leitura obscurecem a situação paradoxal em que a desconstrução opera. Enquanto se dirigem ao sentido como um problema de leitura, como um resultado da aplicação de códigos e convenções, essas histórias vêm se basear no texto como fonte de percepções, sugerindo que se deva outorgar alguma autoridade ao texto, de modo a tentar aprender com ele, até mesmo quando o que se aprende sobre textos e leituras traz ao questionamento a afirmação de que qualquer coisa específica esteja definitivamente no texto. ${ }^{8}$

O controle sobre o sentido é uma operação recorrente e tão antiga 
quanto à própria filosofia ${ }^{9}$. A oposição hierárquica entre voz e escritura é o desejo da filosofia de tornar transparente para si o acesso à verdade, ao significado originário ou final/definitivo, sem contingências, indecisões e opacidades que marcam a escritura. O privilégio platônico da fala - da transparência, da imediatez e presença diante do próprio falante e do ouvinte - sobre a escritura - a mediação, a materialização e ausência do autor ou do leitor - não é contingencial: deu à filosofia o privilégio de ascender à essência, ao significado originário dos conceitos. A verdade, o sentido, as almas poderiam ser acessados pela fala e a escritura sua representação. Para Aristóteles, "os sons emitidos pela voz [...] são os símbolos dos estados da alma [...] e as palavras escritas os símbolos das palavras emitidas pela voz, (...)" ${ }^{10}$. A oposição hierarquizada fala/escritura produziu diversas outras (dentre elas, o signo linguístico, o significado que se acessa mediante o significante, seu invólucro exterior e transparente), como modo de salvaguardar a filosofia mesma em sua capacidade de controlar o processo de significação. A origem e a forma de cada coisa seriam acessíveis, estáveis e fundamentadas se o que impedisse seu acesso fosse excluído, por exemplo, nas derivações o segundo termo dos pares "imaterial"/"material", "verdade"/"falso", "alma"/"corpo". É o polo relacionado ao material, ao falso, ao corpo, que eliminado garante o valor positivo e primário ao primeiro.

Contudo, sabemos que a temática do signo é, desde cerca de um século, o trabalho de agonia de uma tradição que pretendia subtrair o sentido, a verdade, a presença, o ser etc., ao movimento de significação. ${ }^{11}$

A fala coincide signo e pensamento, não produz distância entre o falante e o seu pensamento, como o que ocorre entre quem escreve e o que escreve "A voz ouve-se - isto é, sem dúvida, o que se denomina a consciência - no mais próximo de si como o apagamento absoluto do significante [...]"12; a diferença de si produzida na escritura, depende do movimento temporalespacial, e não da coincidência.

9 DERRIDA, Jacques. Posições. Belo Horizonte: Autêntica, 2001; Gramatologia. 2a Ed. São Paulo: Ed. Perspectiva, 999; SPIVAK, Gayatri C. Translator's Preface in DERRIDA, Jacques. Of Grammatology. Baltimore, Maryland: John Hopkins University, 1997; CULLER, 1997

10 ARISTÓTELES Apud. DERRIDA, 1999, p. 13

11 DERRIDA, 1999, p. 17

12 DERRIDA, 1999, p. 24 
No entanto, prova-se que não é mais fácil dizer o que está na experiência do leitor ou de um leitor do que o que está no texto: a "experiência" é dividida e diferida - está atrás de nós, como algo a ser recuperado, embora ainda esteja à nossa frente como algo a ser produzido. ${ }^{13}$

Esta diferença, que se produz no distanciamento de si, o diferimento, também pertence à experiência do leitor, é o que faz com que as leituras sejam sempre distintas entre si e não idênticas como as teorias fazem crer.

A experiência diferida da leitura também será lembrada pelas teorias feministas da literatura, no entanto, como afirmação destes estudos e problematização do lugar do leitor. À acusação de apelação emocional e excesso de especificidade, estudos feministas contestaram aprofundando a investigação racional de clássicos da literatura e da crítica tradicional em sua racionalização e universalidade. Ao reconhecerem que, no mundo de tradição de autores e leitores masculinos, ser mulher não é o suficiente para se ler como uma, pois frequentemente as mulheres se identificam com as narrativas masculinas, contrariando os próprios interesses; os estudos propuseram a hipótese de uma leitora, como as "histórias de leitura" fazem, rejeitando o lugar do leitor como natural, contínuo. A conclusão a que chegaram foi que os limites temáticos, o preconceito dirigido ao gênero feminino e ao universo da casa (trabalho braçal, cuidado e o cotidiano) nas obras e pelos críticos eram de caráter bem mais específico e apelativo ao "chauvinismo masculino" ${ }^{14}$, do que imaginavam.

\footnotetext{
Uma mulher ler como uma mulher não significa repetir uma identidade ou experiência que é dada, mas assumir um papel que ela constrói com referência à sua identidade como mulher, que é também uma construção, de modo que a série pode continuar: uma mulher lendo como uma mulher lendo como uma mulher. A não-coincidência revela um intervalo, uma divisão interna à mulher ou a qualquer sujeito leitor e à "experiência" daquele sujeito. ${ }^{15}$
}

A admissão do papel de leitora como construção, implicou no reconhecimento do lugar do leitor como específico, menos universal, pois, menos abrangente do que julgavam ser. A investigação minuciosa da crítica

\footnotetext{
13 CULLER, 1997, p. 97

14 CULLER, 1997, p. 70

15 CULLER, 1997, p. 77
} 
tradicional e dos clássicos, bem como a proposição hipotética do papel de leitora mostrou o quanto as "histórias de leitura" funcionam na ordem do artifício racional e não de uma suposta naturalidade ou espontaneidade, cindindo a "experiência" do leitor pela ocupação de um lugar.

\title{
O artifício e o espectador-aprendiz
}

A transfiguração do lugar-comum ${ }^{16}$, de Arthur Danto, não é uma "história de leitura", é uma proposição para uma definição ontológica da arte. No entanto, esta aproximação é possível à medida que o próprio desenvolvimento teórico a propõe, são exemplos hipotéticos de experiências de espectadores que apoiam as justificativas lógicas da obra. São distintas hipóteses de espectador, em diferentes circunstâncias, e algumas com endereçamentos bem precisos: os "sensíveis bárbaros" (estetas kantianos sem definição de arte); o "homem comum" ${ }^{18}$ (sem as motivações do artista moderno, apenas vê tinta preta sobre tela branca); o "esteta" contemporâneo (e seu duplo partidário da art brut); o jovem artista contemporâneo J ( e a teoria da institucionalidade); e outros menos endereçados, mas tão específicos quanto, que compõem o pequeno grupo que debate, observa e discute obras de arte. O que há em comum entre eles é que não distinguem (e se o fazem, não sabem explicar por que) a obra do objeto com o qual compartilha a contraparte material - condição para a definição ontológica proposta pelo autor. Abaixo, autor e espectadores anônimos são instados a lidar com esta (in)distinção.

\begin{abstract}
Mas o que dizer então da cama de J, que, sendo uma obra de arte, é exatamente igual a uma cama comum porque de fato é uma cama comum? "Experimentem", diz-nos J, "deitem na cama", "não tem nada demais nisso" etc. Cautelosamente aceitamos o convite; cautelosamente porque sabemos o que fazer com as camas mas ficamos tremendamente inseguros quando se trata do que fazer com obras de arte que por acaso são camas. Diante de uma cama comum, frases animadoras como essas nos pareceriam enigmáticas. ${ }^{19}$
\end{abstract}

16 DANTO, Arthur, C A Transfiguração do Lugar-Comum: Uma filosofia da arte. São Paulo: Cosac Naify, 2010.

17 DANTO, 2010, p. 166

18 DANTO, 2010, p, 198

19 DANTO, 2010, p. 55 
Não é apenas a definição ontológica da arte que participa destas experiências, questões associadas à estética, às próprias estratégias do espectador e às reações às operações metafóricas da obra, também mobilizam o hipotético público. Por exemplo, no prefácio à edição brasileira, de modo simplificado:

\begin{abstract}
A interpretação de obras de arte é o cerne do exercício da crítica de arte. O crítico procura identificar o significado de uma obra e mostrar como o objeto em que o significado está corporificado efetivamente o incorpora. Uma definição tão simples da interpretação evidentemente deixa de lado uma grande parte do quadro observado, mas chamo a atenção para os dois termos operativos: obra e o objeto. O problema fundamental da filosofia da arte é explicar como a obra se relaciona com o objeto. A obra é o objeto mais o significado, e a interpretação explica como o objeto traz em si o significado que o observador - no caso das artes visuais - percebe e ao qual reage de acordo com o modo como o objeto o apresenta. ${ }^{20}$ (grifos nossos)
\end{abstract}

Em linhas gerais, o espectador de obras reage ao modo como o objeto incorpora o significado; sua reação é consciente, ativa e, assumidamente, artificial, construída pelo conhecimento; a obra possui operações específicas, se apropria metaforicamente de objetos, produz significados e espaços vazios estruturados retoricamente, como o entinema, aos quais o espectador reage e explica.

Às experiências ilustrativas, o texto responde frequentemente com a prescrição de ações, o que é coerente com a noção de que as "histórias de leitura" instruem à ocupação de um lugar.

É instrutivo especular sobre como se veria a pintura não só se não conhecêssemos a história de Ícaro, mas também se, conhecendo-a, não soubéssemos de sua pertinência para a obra, caso o título tivesse se perdido ou o quadro nunca tivesse recebido um título. [...] E isso significa admitir a possibilidade de diferentes estruturações. Se for uma obra de arte, não haverá maneira neutra de olhá-la; melhor dito, olhá-la de maneira neutra é não vê-la como uma obra de arte. ${ }^{21}$

O espectador interpreta a obra (do maneirista Pieter Bruegel, Paisagem com a Queda de Ícaro), ao agir de modo específico, identificando elementos (manchas de tinta com figuras, figuras com personagens e histórias e 
estruturas narrativas, título com os elementos internos, obra e autor com o período histórico) e os combinando na estruturação da obra. Ambas interpretação e estruturação da obra - são função do conhecimento do espectador, de modo que "os limites da interpretação, assim como os da imaginação, são os limites do conhecimento." ${ }^{22}$; e a estruturação se transforma na mesma razão do conhecimento do espectador. À questão levantada sobre a espontaneidade das ações, pode ser respondida pelo seguinte trecho:

Tudo o que dissemos subscreve a ideia, que pode ser vista como um prêmio de consolação aos não artistas, de que a reação a uma pintura complementa sua criação, de modo que o espectador oferece ao artista uma espécie de colaboração espontânea, tal como na relação entre o leitor e o escritor. ${ }^{23}$

O artifício do lugar do espectador constitui esta proposição para uma definição ontológica da arte; o que não deixa de ser interessante, se levarmos em conta que, se as "histórias de leituras" tratam do leitor de ficção (sendo o livro por excelência o lugar do artifício, do aprendizado, do não-saber, dos espaçamentos "entre" os termos, dos "intervalos sem os quais os termos 'plenos' não significariam, não funcionariam" 24 que sinalizam diferenças e divisões nas experiências), a do espectador da experiência do público de obras de arte visuais e plásticas (que são "observáveis" e associadas à naturalidade da visão, à continuidade entre imagem e mundo, à própria história da arte que naturalizou a experiência em diferentes períodos).

Porém, se a definição ontológica da arte se apoia na distinção entre objeto e obra, esta não é condição apenas para sua proposição, mas é antes para qualquer espectador de obras. O artifício da experiência do espectador de Arthur Danto não pertence apenas às suas estratégias de interpretação de obras, mas é condição de sua experiência - o que a torna tão artificial quanto a de qualquer o leitor de textos. "Ver uma obra sem saber que ela é arte é como ter a experiência da matéria impressa antes de aprender a ler"25. Não é por acaso que para cada hipótese de espectador de obras, 
há quase um equivalente literário, senão teatral e musical. Para o autor, apreciar arte, de maneira geral, é sempre da ordem do artifício, sem com isso ignorar as especificidades de cada gênero.

Retornando às hipóteses de espectador, das quais o autor lança mão, J se destaca por ser inspirado abertamente em um aluno, e traz ao texto a função do aprendiz, do não-saber e da divisão inerente à experiência mesmo quando é descrito como refratário à aprendizagem. O espectadoraprendiz abre espaço para as explicações fundamentadas do autor, ao mesmo tempo em que é também o lugar da diferença (desconsiderada pelos que automatizaram o aprendizado) própria ao processo de significação. Por exemplo, em uma pesquisa sobre os visitantes das grandes exposições é possível perceber a quantidade de ações praticadas diante de obras que serão posteriormente descartadas ou excluídas de suas "experiências", no processo de aprendizado de ser espectador de obras:

De tudo o que visitantes fazem juntos numa exposição de arte - observar obras, ler placas, etiquetas e textos afixados em paredes, brincar, estudar, acompanhar o monitor, namorar etc. - , conversar talvez seja a prática mais frequente. ${ }^{26}$

Porém, ao mesmo tempo, é em J onde também incide a especificidade do pertencimento social, da história, do humor, da política.

\begin{abstract}
Um jovem artista mal-humorado e de ideias igualitárias, [...] mostra-se indignado com o que considera a "injustiça hierárquica" de atribuir o status superior de obra de arte à maioria dos itens de minha exposição e de simultaneamente negá-lo a um objeto que em todos os detalhes visíveis se assemelha aos demais. Tomado por uma espécie de furor político, J produz um trabalho idêntico ao meu simples retângulo de tinta vermelha, e asseverando que sua pintura é uma obra de arte exige que eu a inclua na minha mostra, o que faço com prazer. ${ }^{27}$
\end{abstract}

A hipótese de uma leitora, porém, serviu para racionalizar quão universais eram as obras e crítica tradicionais, contrariamente a J que não aprofunda qualquer investigação; seu caminho é intuitivo e sensível, e quem

26 DABUL, Ligia. Conversas em exposição: sentidos da arte no contato com ela. Arte \& Ensaios in Revista do Programa de Pós-Graduação em Artes Visuais, Rio de Janeiro, EBA, UFRJ. Ano XV, n. 16, julho de 2008, p. 55 Disponível em: <http://www.massmoca.org/ lewitt/walldrawing.php?id=88>. Acesso Em 16 abril 2020

27 DANTO, 2010, p. 35 
racionaliza a investigação sobre a experiência do espectador é o próprio autor, ao fazer coincidir a pergunta dos espectadores hipotéticos com a sua, sobre a distinção entre obra e objeto.

No entanto, a necessidade de determinar esta distinção retirou de alguns tipos socioculturais - que compõem o pequeno grupo de espectadores hipotéticos - a possibilidade de afirmarem suas diferenças.

\begin{abstract}
Alguns povos tribais creem que as experiências vividas nos sonhos realmente acontecem e descartam as evidentes incoerências da seguinte maneira: durante o sono a pessoa deixa seu corpo por algum tempo e vai ocupar um outro, e é nesse corpo que ela passa, realmente, pelas experiências que nós dizemos não ter sido vividas, mas sonhadas. As distorções que geralmente consideramos típicas dos sonhos são explicadas - felizmente - pela dificuldade de trocar de corpo. ${ }^{28}$
\end{abstract}

Claro é que compreendemos o que o autor afirma sobre "sair" de um corpo e "entrar" em outro, mas não deixa de ser ilustrativo que a experiência de "povos tribais" se dê em sonhos, processos inconscientes ou em transe; pois, os sonhos e o inconsciente são os lugares desta unidade fantasiosa entre corpos e do corpo consigo mesmo. Se a hipótese da leitora rompe racionalmente com a experiência biológica e social de ser mulher, é porque ser mulher num mundo de homens significa inconscientemente se identificar com eles, seu corpo e projeções. De modo inconsciente, nos sonhos, estes corpos produzem "realmente" identidade, a "pessoa deixa seu corpo por algum tempo e vai ocupar um outro". É somente quando se explicita a solicitação, enquanto artifício, que a diferença também se explicita. "Apela à condição de ser mulher como se fosse um dado e, simultaneamente, insta que essa condição seja criada ou conquistada".

A matéria do corpo e sua estabilidade, num mundo de projeções e sonhos, podem parecer estranhas à crítica desconstrucionista da metafísica que elege a imaterialidade, transparência e imediatez como polos positivos, frente à materialidade, opacidade e mediação da escritura. Mas é válido lembrar também, e isto será retomado mais à frente, que os polos binários funcionam à medida que a exclusão permite o acesso à verdade e o controle do sentido; de outro modo não se justificariam. Abaixo, um trecho que retoma a questão da identidade física, material, e seus "fantasmas", 
enquanto projeções reprodutivas.

Ora, há um familiar problema de ordem metafísica concernente à identidade de uma obra de arte. O problema aparece quando observamos as várias impressões de um mesmo poema: será ele idêntico a essas impressões ou terá cada uma identidades completamente diferentes? ${ }^{30}$

A desconstrução responderia associando a metafísica ao desejo de garantia da verdade e do controle do sentido, ao eleger a estabilidade de alguns elementos à custa de outros, e o principal deles é a oposição natureza/ cultura que dá à matéria o acesso físico imediato. Sempre que um dos polos designar o acesso à verdade, seu oposto será destituído, com o objetivo de aferir prioridade ao primeiro. Abaixo, um posicionamento da teórica Gayatri Spivak sobre questão semelhante, citada acima.

\begin{abstract}
Então, o que é a identidade do livro? Ferdinand de Saussure assinalou que o "mesmo" fonema pronunciado duas ou por pessoas diferentes não é idêntico a si mesmo. Sua única identidade reside em sua diferença de todos os outros fonemas [...]. Portanto, duas leituras do "mesmo" livro mostra uma identidade que só pode ser definida como diferença. O livro não é repetível em sua identidade: cada leitura do livro produz um simulacrum de um "original" que é em si a marca do assunto mutável e instável que Proust descreve, usando e sendo usado por uma linguagem também mutável e instável. ${ }^{31}$
\end{abstract}

Um mundo menos complexo, dual, em que se pode excluir como secundário o que problematiza os limites e as fronteiras é o que está sendo colocado. Não se trata de afirmar que não há diferença entre ficção e realidade, tampouco que a experiência do espectador de ficção e de obras de arte não possa ser pensada, mas que deve levar em conta sua complexidade e o lugar da diferença, necessários ao processo de significação.

Quando dizemos "é um sonho", "é um reflexo", "é um eco", introduzimos um amortecedor de choques no sistema de crenças que define o mundo de modo conservador, já que expulsa para um espaço ontologicamente diferente entidades que, se fossem aceitas no mundo, complicariam demais o sistema. ${ }^{32}$

O "amortecedor de choques" não funciona apenas no mundo conservador,

30 DANTO, 2010, p. 73

31 SPIVAK, 1997, p. xi (tradução livre)

32 DANTO, 2010, P. 53 
mas em qualquer um que "expulse" a diferença com receio de complicar o "sistema"; distinguir realidade de aparência deve ser possível sem que tenhamos que "expulsar" juntamente parte dos habitantes do mundo que não respondem à simplificação.

Em outro trecho, a "necessidade" de rejeitar as aparências entre os membros de uma família como condição de pertença, Danto reduz a família às afiliações genéticas, o que é bem questionável:

O uso do conceito de família para designar esse cruzamento de propriedades fenotípicas é muito mal escolhido, porque os membros de uma família, quer se pareçam muito ou pouco, devem ter obrigatoriamente afiliações genéticas comuns que explicam suas "semelhanças de família". Nenhuma pessoa é membro de uma familia se the faltam essas afinidades, mesmo que se pareça com este ou aquele parente. ${ }^{33}$ (grifos nossos)

Para justificar a teoria aristotélica (o prazer do conhecimento de que se trata de imitação é a base para a tese do duplo artifício na experiência do espectador, que distingue obra do objeto, e depois se lança às estratégias de interpretação), acaba por destituir de valor a identidade enquanto experiência social e biológica, e a diferença enquanto sua constituição:

Onde está a diferença entre um travesti e um homem que interpreta papeis femininos, supondo que ambos estão imitando mulheres? Imagino que, de certa forma, o travesti está fingindo ser uma mulher e espera que as pessoas acreditem que ele é uma mulher, escondendo sua verdadeira identidade com trejeitos patéticos. [...] Mas acho que podemos tirar outras conclusões. Os gestos daquele que interpreta o papel de uma mulher dizem respeito a mulheres, ao passo que a mimese efeminada do travesti não tem nenhum cunho semântico. ${ }^{34}$

O fracasso da travesti na citação está associado à tese aristotélica de que o prazer coincide com o conhecimento sobre o fingimento. $E$, nos perguntamos, se o correspondente no mundo do artista que interpreta outro gênero é mesmo a travesti ou é o tipo da personagem que interpreta - uma mãe, um carteiro, o vendedor - sendo o prazer da "farsa" apenas um dos gêneros de interpretação? Na tentativa de provar uma tese associa-se a travesti, seu corpo, sua identidade - sua diferença - ao fracasso do prazer pelos "trejeitos patéticos" e pela "mimese efeminada", sendo duplamente 
expulsa - do mundo que não admite a complexidade; e da capacidade de dar prazer, única função até então admitida.

Os polos em oposição não são apenas recursos teóricos que a desconstrução utiliza para explicar a violência com que a metafísica hierarquiza as binariedades; eles regulam, a partir de uma oposição, todas as outras, levando de roldão o movimento de significação. O cunho semântico, ao final da citação, de que os gestos dizem respeito às mulheres, enquanto a mimese da travesti não diz respeito a nada, está em acordo com a distinção proposta entre objetos e obras, sendo as primeiras literais e as segundas metafóricas; uma coisa do mundo não significa, ao passo que uma obra, sim. $\mathrm{E}$, isto é facilmente questionável se retomarmos $\mathrm{R}$. Barthes e a mitologia, ou a cultura de massa. Os polos podem também facilmente produzir enganos se isto trouxer garantias de verdades. A valorização da escritura durante a Idade Média estava associada ao "livro da natureza" e à "escritura de Deus"; enquanto a escrita no mundo era tomada como literal. A citação precisa sobre como a metáfora também cria literalidade, dá à matéria (tão desprezada pela tradição metafísica avessa à diferença espaço-temporal) caráter de estabilidade, desde que se ganhe com isso o controle sobre o sentido.

O paradoxo a que devemos estar atentos é então o seguinte: a escritura natural e universal, a escritura inteligível e intemporal recebe este nome por metáfora. A escritura sensível, finita, etc., é designada como escritura no sentido próprio; ela é então pensada do lado da cultura, da técnica e do artifício: procedimento humano, astúcia de um ser encarnado por acidente ou de uma criatura finita. [...] Não se trataria, portanto, de inverter o sentido próprio e o sentido figurado, mas de determinar o sentido "próprio" da escritura como a metaforicidade mesma. ${ }^{35}$

O que está em jogo é a oposição binária de exclusão; pode-se atribuir qualquer "coisa", "ação", "pessoa" a um do polos elevando-a ou rebaixando-a, conforme as garantias e acessos. A especificidade do espectador, destacada por J, em vez de apontar para os limites da universalidade, reforça-os ainda mais, idealizando-a, quando as diferenças são lançadas para fora pela delimitação entre realidade e aparência. O artifício da "experiência" deveria ser a afirmação do não-natural, da descontinuidade entre "espectador" observando obras como "espectador", mas, quando o artifício promete o não engano ou o "por detrás da aparência" recaímos novamente numa universalidade que se afirma pela idealização e expulsão da diferença para sua exterioridade. 


\section{Conclusão}

As "histórias de leituras", ao associarem o sentido da ficção às experiências idealizadas dos leitores, acabam por propor o controle do sentido da obra. A experiência do leitor não é reconhecida em seu artifício, como ocupação de um lugar ou como a proposição racional hipotética de um papel, como fizeram alguns movimentos feministas. É somente de modo altamente artificializado que se pode compreender este papel, pois se há estratégias dos leitores e espectadores, bem como operações de textos e obras, uma vez aprendidos, não haveria sentido em ocupar este lugar. Leitor e espectador "colaboram" com a obra, como nos lembram o filósofo Arthur Danto e o teórico Jonathan Culler. A especificidade da experiência está associada à exclusão de todas as ações que não pertencem ao lugar ocupado, bem como à proposição dos estudos feministas de descontinuidade entre identidade social e biológica, e hipotética. A hiperracionalização não leva à universalização da experiência, mas à sua especificidade, pois traz à superfície das ações naturalizadas o que foi excluído. A leitura do espectador de A transfiguração do lugar-comum, de A. Danto, parte da aproximação feita pela própria obra entre justificativa teórica e hipótese de experiência do espectador. O artifício aparece como dimensão importante da experiência, já que o conhecimento adquirido é o que rege as estratégias do espectador, numa dupla situação experiência do espectador em distinguir obra de objeto $z$ (o que coincide com a condição ontológica para definição de arte), que é condição para a experiência de interpretação (identificações e relações entre si). Porém, a especificidade do espectador de obras, diferentemente, do que ocorrem com os movimentos feministas, não questiona a universalidade do que se coloca tradicionalmente, ao contrário, acaba por afirmá-la, a partir de oposições binárias bem conservadoras, como as que opõem "povos tribais" à racionalidade filosófica, a genética às relações afetivas, a fantasia da unidade identitária à sua complexidade. Esta investigação é vista pela perspectiva dos estudos desconstrucionistas, de que a tradição filosófica instala a distinção entre fala e escritura como garantia de acesso à verdade e ao sentido transcendental, originário e definitivo. Pois a escritura, enquanto artifício, por excelência, remete ao aprendizado, ao não-saber, ao espaçamento "entre", à ausência entre autor e leitor; e fala passa a ser o oposto disso tudo, onde o acesso e garantia se dão. Ao fim, o que se deseja é excluir a diferença como complexidade do mundo, simplificá-lo e para isso, excluir, expulsar e afirmar sua identidade. 